\title{
Stakeholder attitudes and needs regarding cell-free fetal DNA testing
}

Melissa Hill ${ }^{1,2}$, Celine Lewis ${ }^{1,2}$ and Lyn S Chitty ${ }^{1,2}$

${ }^{1}$ North East Thames Regional Genetics Service, Great Ormond Street Hospital for Children NHS Foundation Trust, London, UK

${ }^{2}$ Genetics and Genomic Medicine, UCL Institute of Child Health, London, UK

\section{Correspondence to:}

Dr Melissa Hill

North East Thames Regional Genetics Service

Level 5, Barclay House

37 Queen Square

London WC1N 3BH

Email: melissa.hill@ucl.ac.uk 
ABSTRACT

\section{Purpose of review}

To explore stakeholder views on cell-free DNA testing and highlight findings important for successful implementation and the provision of best practice in counselling.

\section{Recent findings}

Non-invasive tests based on the analysis of cell-free fetal DNA are now widely available in clinical practice and applications are expanding rapidly. It is essential that stakeholder views are considered in order to identify and address any ethical and social issues. We provide an overview of stakeholder viewpoints and then focus on the key issues of informed decision making, test uptake, service delivery and information sources.

\section{Summary}

Stakeholders are positive about the introduction of cell-free fetal DNA testing into clinical practice. They describe both practical and psychological benefits arising from tests that are safe and can potentially be performed earlier in pregnancy. Key concerns, which include the potential for these tests to have a negative impact on informed decision making and increased societal pressure to have testing, can be addressed through careful parent-directed counselling. As applications for these tests expand it is increasingly important to develop innovative approaches to facilitate good understanding for parents who are offered non-invasive prenatal testing.

\section{Keywords}

cell-free fetal DNA, non-invasive prenatal testing and diagnosis, stakeholder viewpoints, counselling

\section{Abbreviations}

cffDNA - cell-free fetal DNA, NIPD - non-invasive prenatal diagnosis, NIPT - non-invasive prenatal testing, NHS - National Health Service, UK - United Kingdom 


\section{INTRODUCTION}

Following the discovery of cell-free fetal DNA (cffDNA) in maternal plasma [1] non-invasive prenatal tests have moved quickly from research to clinical practice. Tests that are currently offered include non-invasive prenatal diagnosis (NIPD) for fetal sex determination, fetal rhesus $D(R H D)$ genotyping and some single gene disorders, and a highly accurate screening test for aneuploidies referred to as non-invasive prenatal testing (NIPT). The rapid speed of translation has been most apparent for NIPT where commercial interests have driven the shift from proof-of-concept studies in 2008 through large scale validation into clinical practice in 2011 (for review see [2]). Now NIPT is offered in more than 90 countries [3] and the technology continues to advance with NIPT utilised to detect not only the common aneuploidies but also rarer chromosomal changes [4].

With technology moving at such a fast pace it is important that studies assessing stakeholder views and attitudes are conducted to ensure ethical and social issues are identified and addressed so that tests can be implemented in a way that meets the needs of service users and providers. Quantitative and qualitative approaches have been used to assess the views of future and current service users, parents of children with disabilities, the general public and health professionals. The majority of studies have focused on NIPT for aneuploidy with researchers gathering views first on the hypothetical use of this test [5-15] and, more recently, on experience drawn from use within clinical practice [1620]. Researchers have also looked at stakeholder views on NIPD for fetal sex determination [21-24], single gene disorders [25-29] and RHD genotyping [30]. The aim of this review was to examine stakeholder views on NIPT/D and draw out key findings that inform best practice for counselling (summarised in Table 1).

\{Sachs, $2015 \# 1775\}\{$ Skirton, 2014 \#1683\}

\section{OVERVIEW OF STAKEHOLDER VIEWPOINTS}


Stakeholder attitudes to non-invasive tests have generally been very positive. The most commonly quoted clinical benefits of NIPT/D are test safety, as the need for invasive testing is either removed or reduced, having results available earlier in pregnancy, the relative ease with which the sample for testing is taken and, as a result, the potential for improved access to prenatal tests $[5,6,10,21,25$ 27]. For NIPT specifically, improvements over traditional screening tests have been highlighted, including greater accuracy, increased certainty about the results and the potential to identify cases of Down syndrome that might otherwise have been missed $[8,11,13,16]$.

Stakeholders have also identified a number of psychological benefits including being able to obtain reassurance without putting the pregnancy at risk $[8,16]$ and more meaningful decision making as couples can decide about prenatal testing without being influenced by fear of miscarriage or uncertainty of results [13]. Many also highlighted the psychological benefits of having results available earlier in pregnancy $[6,12,13,26]$. For couples choosing to terminate the pregnancy, an earlier termination was thought to be easier emotionally and more acceptable from an ethical or moral viewpoint. For couples deciding to continue with an affected pregnancy, there is more time to come to terms with the diagnosis, adjust to the information and seek support.

The most common concerns about NIPT/D focus on the potential for routinisation of testing and the resultant negative impact on informed choice. Many stakeholders felt that NIPT/D had the potential to be seen as routine or expected as the tests are safe and easy to perform or that NIPT/D may be viewed as "just another blood test" as there are so many blood tests during pregnancy $[7,8,26,27$, 29]. If NIPT/D is seen as routine parents may not give sufficient thought to the implications of testing which could then hinder informed decision making. Another frequently raised concern was that parents may feel increased pressure to have testing because NIPT/D is safe $[8,13,26,27]$ as the removal of risk to the pregnancy means that there is no "excuse" to decline testing. Feelings of pressure could also arise from how the test is described or simply because it is offered by a "trusted" 
health professional [8]. Stakeholders also discuss how any increase in prenatal testing and terminations could lead to a reduction in support structures and resources for children with disabilities and a society less tolerant in their attitudes to people who have children with disabilities, all of which could further increase feelings of pressure to undertake testing and terminate an affected pregnancy $[8,9,13]$. Cost has been highlighted as a concern that will impede equity in access in countries where parents have to pay for testing [33]. Other concerns centre on the applications of NIPT/D and the potential to 'misuse' the technology for sex selection, less serious indications or testing for late onset conditions $[8,13,15]$.

\section{INFORMED DECISION MAKING}

The potential for non-invasive tests to have a negative impact on informed decision making is a key concern that is relevant to all applications of non-invasive tests, but is particularly heightened for Down syndrome screening with NIPT as numerous studies have shown that uninformed decisions are common for women offered traditional screening tests [34, 35]. In addition, women from multiple countries and cultures have been shown to emphasise test safety when making decisions about prenatal testing $[28,36-38]$ which suggests choices may not be informed as other attributes of NIPT/D have not been considered. There is also evidence that women and health professionals do not see the same need for written consent and time for reflection about testing with NIPT as they do with invasive testing which suggests that the goal of making an informed decision may not be as clear as it would be with an invasive test $[39,40]$. Furthermore, as reassurance has been identified as an important motivator for accepting NIPT $[16,19]$, approaches to counselling that omit discussing the implications of a positive result, including views on termination or the value of children with disabilities, may mean that women defer thinking about these issues, compromising informed decision making and potentially leaving them unprepared for a positive result [41]. For this reason, individualised post-test counselling and options for ongoing support are critical to help parents who are given an abnormal 
result to understand the clinical implications and to provide support for decision making about next steps $[42,43]$.

The first studies to measure informed decision making [19] or assess contributing factors such as knowledge $[20,44]$ when offering NIPT in clinical practice are now emerging. A study from the United Kingdom (UK) looking at the introduction of NIPT into the state funded National Health Service (NHS) used a formal measure of informed choice and found rates of informed choice were high (89\%) in 585 women offered NIPT. Further assessment is needed to determine whether this finding reflects NIPT being offered in a research setting with additional time available for pre-test counselling [19]. In a study to assess understanding of NIPT amongst Latina women, Farrell et al [20] found that knowledge was lower for women who had declined NIPT. As low knowledge will hinder informed decision making this study highlights the need for culturally specific information and support in our increasingly multicultural societies [20].

Stakeholders consistently report that concerns about informed decision making could be overcome by careful pre-test counselling and a strong focus on the consent procedure $[8,29]$. When discussing ways of supporting informed decision making, stakeholders suggest the provision of both spoken and written information and support the use of formal consent processes to underscore how NIPT/D is different from other blood tests in pregnancy $[11,12,29]$. Counselling to promote informed decision making should include the benefits and limitations of NIPT/D, with health professionals taking care not to focus solely on discussing the safety of NIPT/D, and alternatives that include the option of not having a test. Health professionals should also provide balanced information on the conditions being tested for, time for reflection and a discourse on the implications of possible test results guided by individual values and preferences [45]. Notably, women having NIPT report that the safety and high accuracy afforded by NIPT do not eliminate anxiety and uncertainty as these feelings are strongly tied 
to the decision of what they would do if the baby is affected [46]. Consequently, it is clear that NIPT does not simplify the decision-making process and parents need individualised support [46].

\section{UPTAKE OF PRENATAL TESTS}

Interest in NIPT/D is high and it is likely that the population opting for prenatal testing will expand as women who would not have previously considered prenatal testing due to the risk of miscarriage would be willing to have NIPT/D $[11,12,26]$. More couples will take up prenatal testing for "information only", seeking reassurance or to plan and prepare for the birth of an affected child rather than using the information to make decisions about termination of pregnancy [10, 12]. This change will impact on clinical services as the numbers of couples seeking prenatal testing will increase. It is also likely that additional support will be required for those families continuing with a pregnancy that is known to be affected.

While it is likely that many parents will opt for NIPT/D, it is critical that health professionals highlight the option of not having any testing and discuss alternative prenatal tests. Studies from the United States and the Netherlands found that one third of people surveyed reported not wanting any tests for Down syndrome $[10,14]$. In addition, the possibility of a false positive and the need for a confirmatory invasive test can lead women to decline NIPT [46]. There is also evidence that some women may prefer to have an invasive test over NIPT/D. Research looking at preferences for prenatal tests in multiple countries found that a large proportion of women from countries such as Italy and Portugal would choose invasive testing, which can give information about a wider range of chromosomal abnormalities, over an NIPT test which only tests for the major trisomies [38]. These women wanted the additional information invasive tests provide compared with NIPT as maximising information was a priority [38]. Women with very high risk results from traditional screening or other 
indications on ultrasound may also prefer to go directly to invasive testing rather than wait for the NIPT result first $[19,47]$.

\section{EXPANDING USES OF NIPT/D}

Generally stakeholders are accepting of non-invasive tests for a wide range of applications, but concerns have been raised about where to "draw the line" [13]. Notably, the speed at which new screening targets are becoming available with NIPT is rapidly outstripping the development of appropriate approaches to counselling and research on stakeholder views. In addition to T21, T18 and T13 several companies now offer testing for sex chromosome aneuploidies, aneuploidies associated with high risk for early pregnancy loss (T9, T16, and T22) and microdeletion syndromes [4]. Very few studies have examined stakeholder views of these new applications for NIPT [11, 14, 48, 49]. Whilst women are generally interested in having tests for sex chromosome aneuploidies and microdeletion syndromes $[11,48,49]$, some question the usefulness of screening for conditions with variable or unknown outcomes [49]. A key finding from this research is that women want to know what is being screened for prior to testing as this information is important for weighing up the advantages and disadvantages of NIPT relative to other options $[11,49]$. Given the expanding range of potential conditions, and their rarity, accurate pre-test counselling will become increasingly challenging. Professional education as well as research into how best to deliver this information is needed as the targets included in NIPT assays will continue to expand and clinicians will be increasingly asked to describe complex test options, testing for multiple conditions and the possibility of uncertain and incidental findings.

\section{SERVICE DELIVERY}


Several studies have addressed how NIPT/D should be delivered. For fetal sex determination and single gene disorders where testing is offered to families known to be at high risk, stakeholders prefer that NIPD continues to be available through specialist genetic or fetal medicine services to ensure appropriate pre- and post-test counselling offered by health professionals with specialist knowledge of the condition and experience and training in counselling for prenatal testing $[21,25,26]$. For NIPT for aneuploidy strategies for implementation are dependent on existing prenatal care practices and may vary between countries. Regardless of where NIPT is offered, pre- and post-test counselling are considered essential $[12,50]$. There is ongoing debate about whether to offer NIPT as a first line or contingent test, particularly in state funded health systems [51]. Many report wanting NIPT offered to all women, but accept that contingent testing may be necessary due to the high current costs $[44,47]$. Results from a survey of health professionals in 28 countries indicates that across and within countries there is wide variation in who is offered NIPT, including high risk women only, all pregnant women, only women who request it or only women who can pay for it [3]. In addition, the cost of NIPT was highly variable and several clinicians suggested that high test costs were limiting implementation and precluding equity of access [3]. Several professional bodies have released guidance on NIPT [52-56] and research with health professionals offering NIPT in the United States shows that this test is largely being implemented according to professional guidelines $[17,18,57]$. However, a cause for concern was evidence that NIPT is being offered as a diagnostic test by a significant portion of providers [17, 57] demonstrating that continuing health professional education and training is essential.

\section{INFORMATION SOURCES}

For couples considering NIPT/D information will be derived from multiple sources. In addition to information garnered from healthcare professionals at clinical appointments, couples may be influenced by what they read in the news media, on websites and in patient information leaflets from providers of non-invasive tests. Studies looking at newspaper articles describing non-invasive tests in 
the UK (79 articles, with 69 on NIPT for DS) [58] and United States (23 articles on NIPT for DS) [59] found that the majority of articles were focused on the benefits of NIPT, such as avoiding the risk of miscarriage, and did not always address concerns or limitations of the technology. Review of 40 websites advertising NIPT for aneuploidy found that, whilst some had balanced and accurate information, the majority did not provide balanced information that matched recommendations from professional guidelines with a key omission being a lack of evidence to support the information provided [60]. Only half of the sites provided information on the need for an invasive test to confirm a positive NIPT result and only one site mentioned the possibility of inconclusive or failed results [60]. As with the news media articles, websites were much more likely to discuss the benefits of NIPT than the limitations of these tests. Similarly, evaluation of the quality of information leaflets from five commercial providers of NIPT found that none of the pamphlets included all of the content recommended by professional bodies [61]. There are, however, a growing number of examples of information leaflets based on guidelines from professional bodies that have been developed by expert panels of clinicians and patient groups and then either reviewed by focus groups with parents [61] or validated with a questionnaire following use in a clinical setting (accessible via www.rapid.nhs.uk).

Health professionals should be aware that when couples attend for pre-test counselling they may have incomplete information or unrealistic expectations about NIPT/D derived from the media or internet. It is therefore important that in addition to giving information, clinicians should check understanding to ensure that misunderstandings arising from other sources have not prevailed.

\section{CONCLUSIONS}

Stakeholders are overwhelmingly positive about the introduction of NIPT/D into clinical practice, welcoming these new tests that are highly accurate and offer a safer approach to prenatal testing. Concerns around the potential for a negative impact on informed decision making and increased 
societal pressure to have testing can be addressed through careful parent-directed counselling. Supporting informed decision making is essential and pre-test counselling should include a discussion of the implications of the test result and allow time for reflection. Post-test counselling is also critical to ensure parents understand the implications of the results and have personalised support and information to aid decision making in pregnancy. This includes making parents aware of the full range of options for prenatal testing available and providing information about the benefits and limitations of each option, including the option not to have testing. In order to deliver such counselling effectively, detailed and comprehensive health professional education is essential.

Continued research considering ethical issues, stakeholder views and implementation strategies is essential to ensure NIPT/D is being offered appropriately. The majority of studies to date have been conducted in the United States, UK, Hong Kong and the Netherlands. More research is needed from other countries as direct comparison between countries has shown clear differences in preferences for prenatal tests [38] and how tests are currently being delivered [3]. Research from specific population groups such as ethnic or religious groups has thus far been limited and more research is needed. In addition, research around stakeholder views of counselling needs has primarily focused on pre-test counselling and informed decision making, while these issues are critical it is important not to overlook what people feel is most helpful for post-test counselling, particularly in situations where parents may not be prepared for an abnormal result.

\section{KEY POINTS}


- Stakeholders are largely positive about the introduction of cell-free fetal DNA testing into clinical practice and highlight both practical and psychological benefits arising from tests that are safe, easy to perform and can potentially provide results earlier in pregnancy.

- The most commonly raised concerns about cell-free fetal DNA testing are the potential for a negative impact on informed decision making and increased societal pressure to have testing, both of which can be addressed through careful parent-directed counselling that includes the benefits and limitations of NIPT/D, alternatives, time for reflection and an individualised discussion of the implications of possible test results.

- Stakeholders are generally accepting of a wide range of applications for cell-free fetal DNA, but as applications expand the counselling process must be adapted to facilitate good understanding of the complex test options, testing for multiple conditions and the possibility of uncertain and incidental findings.

- Health professional education will be essential if counselling is to be delivered effectively

\section{Acknowledgements}

None.

\section{Financial support and sponsorship}

LSC is funded by the NIHR Biomedical Research Centre at Great Ormond Street Hospital for Children. $\mathrm{MH}$ and $\mathrm{CL}$ are funded by the National Institute for Health Research (NIHR) under the Programme Grants for Applied Research programme (RP-PG-0707-10107) (the "RAPID" project). The views expressed are those of the authors and not necessarily those of the NHS, the NIHR or the Department of Health. 


\section{Conflicts of interest}

There are no conflicts of interest.

\section{REFERENCES AND RECOMMENDED READING}

Papers of particular interest, published within the annual period of review, (2014-2015) have been highlighted as:

- of special interest

• of outstanding interest

1. Lo YM, Corbetta N, Chamberlain PF, et al. Presence of fetal DNA in maternal plasma and serum. Lancet 1997; 350:485-7.

2. Twiss $\mathrm{P}$, Hill M, Daley R, Chitty LS. Non-invasive prenatal testing for Down syndrome. Semin Fetal Neonatal Med 2014; 19:9-14.

3. Minear MA, Lewis C, Pradhan S, Chandrasekharan S. Global perspectives on clinical adoption of NIPT. Prenat Diagn 2015; 35:959-67.

- This questionnaire study looking at the views of health professional from around the world highlights differences in how NIPT is being offered within and across countries.

4. Hayden EC. Prenatal-screening companies expand scope of DNA tests. Nature 2014; 507:19.

5. Kooij L, Tymstra T, Berg P, et al. The attitude of women toward current and future possibilities of diagnostic testing in maternal blood using fetal DNA. Prenat Diagn 2009; 29:164-8.

6. Tischler R, Hudgins L, Blumenfeld YJ, et al. Noninvasive prenatal diagnosis: pregnant women's interest and expected uptake. Prenat Diagn 2011; 31:1292-9.

7. Kelly SE, Farrimond HR. Non-invasive preantal genetic testing: A study of public attitudes. Public Health Genomics 2012; 15:73-81. 
8. Lewis C, Silcock C, Chitty LS. Non-invasive prenatal testing for Down's syndrome: pregnant women's views and likely uptake. Public Health Genomics 2013; 16:223-32.

9. Kellogg G, Slattery L, Hudgins L, Ormond K. Attitudes of mothers of children with down syndrome towards noninvasive prenatal testing. J Genet Couns 2014; 23:805-13.

10. Allyse M, Sayres LC, Goodspeed TA, Cho MK. Attitudes towards non-invasive prenatal testing for aneuploidy among US adults of reproductive age. J Perinatol 2014; 34:429-34.

11. Farrell RM, Agatisa PK, Nutter B. What women want: lead considerations for current and future applications of noninvasive prenatal testing in prenatal care. Birth 2014; 41:276-82.

12. Lewis $\mathrm{C}$, Hill $\mathrm{M}$, Silcock $\mathrm{C}$, et al. Non-invasive prenatal testing for trisomy 21: a cross-sectional survey of service users' views and likely uptake. BJOG 2014; 121:582-94.

13. van Schendel RV, Kleinveld JH, Dondorp WJ, et al. Attitudes of pregnant women and male partners towards non-invasive prenatal testing and widening the scope of prenatal screening. Eur J Hum Genet 2014; 22:1345-50.

14. van Schendel RV, Dondorp WJ, Timmermans DR, et al. NIPT-based screening for Down syndrome and beyond: what do pregnant women think? Prenat Diagn 2015; 35:598-604.

15. Farrimond HR, Kelly SE. Public viewpoints on new non-invasive prenatal genetic tests. Public Underst Sci 2013; 22:730-44.

16. Yi H, Hallowell N, Griffiths S, Yeung Leung T. Motivations for undertaking DNA sequencingbased non-invasive prenatal testing for fetal aneuploidy: a qualitative study with early adopter patients in Hong Kong. PLoS One 2013; 8:e81794.

17. Horsting JM, Dlouhy SR, Hanson K, et al. Genetic counselors' experience with cell-free fetal DNA testing as a prenatal screening option for aneuploidy. J Genet Couns 2014; 23:377-400.

18. Buchanan A, Sachs A, Toler T, Tsipis J. NIPT: current utilization and implications for the future of prenatal genetic counseling. Prenat Diagn 2014; 34:850-7. 
19. Lewis C, Hill M, Skirton H, Chitty LS. Development and validation of a measure of informed choice for women undergoing non-invasive prenatal testing for aneuploidy Eur J Hum Genet 2015; [Epub ahead of print].

- First study to measure informed decision making when NIPT is offered in a clinical practice setting.

20. Farrell R, Hawkins A, Barragan D, et al. Knowledge, understanding, and uptake of noninvasive prenatal testing among Latina women. Prenat Diagn 2015; 35:748-53.

21. Lewis C, Hill M, Skirton H, Chitty LS. Fetal sex determination using cell-free fetal DNA: service users' experiences of and preferences for service delivery. Prenat Diagn 2012; 32:735-41.

22. Lewis C, Hill M, Skirton H, Chitty LS. Non-invasive prenatal diagnosis for fetal sex determination: benefits and disadvantages from the service users' perspective. Eur J Hum Genet 2012; 20:1127-33.

23. Hill $M$, Compton $C$, Lewis $C$, et al. Determination of foetal sex in pregnancies at risk of haemophilia: a qualitative study exploring the clinical practices and attitudes of health professionals in the United Kingdom. Haemophilia 2011; 18:575-83.

24. Alexander E, Kelly S, Kerzin-Storrar L. Non-invasive prenatal testing: UK genetic counselors' experiences and perspectives. J Genet Couns 2015; 24:300-11.

25. Lewis C, Hill M, Chitty LS. Non-invasive prenatal diagnosis for single gene disorders: experience of patients. Clin Genet 2014; 85:336-42.

26. Hill $M$, Compton $C$, Karunaratna $M$, et al. Client views and attitudes to non-invasive prenatal diagnosis for sickle cell disease, thalassaemia and cystic fibrosis. J Genet Couns 2014; 23:1012-21.

27. Hill M, Karunaratna M, Lewis $\mathrm{C}$, et al. Views and preferences for the implementation of noninvasive prenatal diagnosis for single gene disorders from health professionals in the United Kingdom. Am J Med Genet A 2013; 161A:1612-8.

28. Hill M, Suri R, Nash E, et al. Preferences for prenatal tests for cystic fibrosis: A discrete choice experiment to compare the views of adult patients, carriers of cystic fibrosis and health professionals. J Clin Med 2014; 3:176-90. 
29. Skirton H, Goldsmith L, Chitty LS. An easy test but a hard decision: ethical issues concerning non-invasive prenatal testing for autosomal recessive disorders. Eur J Hum Genet 2015; 23:1004-9.

30. Oxenford K, Silcock C, Hill M, Chitty L. Routine testing of fetal Rhesus D status in Rhesus D negative women using cell-free fetal DNA: an investigation into the preferences and information needs of women. Prenat Diagn 2013; 33:688-94.

31. Skirton H, Goldsmith L, Jackson L, et al. Offering prenatal diagnostic tests: European guidelines for clinical practice. Eur J Hum Genet 2014; 22:580-6.

32. Sachs A, Blanchard L, Buchanan A, et al. Recommended pre-test counseling points for noninvasive prenatal testing using cell-free DNA: a 2015 perspective. Prenat Diagn 2015; 35:968-71.

33. Allyse M, Sayres LC, Goodspeed T, et al. "Don't want no risk and don't want no problems": Public understandings of the risks and benefits of non-invasive prenatal testing in the United States. AJOB Empir Bioeth 2015; 6:5-20.

34. Michie S, Dormandy E, Marteau TM. The multi-dimensional measure of informed choice: a validation study. Patient Educ Couns 2002; 48:87-91.

35. van den Berg $M$, Timmermans DR, Ten Kate $L P$, et al. Are pregnant women making informed choices about prenatal screening? Genet Med 2005; 7:332-8.

36. Hill M, Fisher J, Chitty LS, Morris S. Women's and health professionals' preferences for prenatal tests for Down syndrome: a discrete choice experiment to contrast noninvasive prenatal diagnosis with current invasive tests. Genet Med 2012; 14:905-13.

37. Beulen L, Grutters JP, Faas BH, et al. Women's and healthcare professionals' preferences for prenatal testing: a discrete choice experiment. Prenat Diagn 2015; 35:549-57.

38. Hill $\mathrm{M}$, Johnson J, Langlois $\mathrm{S}$, et al. Preferences for prenatal tests for Down syndrome: an international comparison of the views of pregnant women and health professionals. Eur J Hum Genet 2015; In press.

39. van den Heuvel A, Chitty L, Dormandy E, et al. Is informed choice in prenatal testing universally valued? A population-based survey in Europe and Asia. BJOG 2009; 116:880-5. 
40. Silcock C, Liao LM, Hill M, Chitty LS. Will the introduction of non-invasive prenatal testing for Down's syndrome undermine informed choice? Health Expect 2015; 18:1658-71.

41. Mozersky J. Hoping Someday Never Comes: Deferring Ethical Thinking About Noninvasive Prenatal Testing. AJOB Empirical Bioethics 2015; 6:31-41.

42. Fisher J. First-trimester screening: dealing with the fall-out. Prenat Diagn 2011; 31:46-9.

43. Fisher J. Supporting parents after disclosure of abnormal first trimester screening results. Curr Opin Obstet Gynecol 2012; 24:109-13.

44. Kou KO, Poon CF, Tse WC, et al. Knowledge and future preference of Chinese women in a major public hospital in Hong Kong after undergoing non-invasive prenatal testing for positive aneuploidy screening: a questionnaire survey. BMC Pregnancy Childbirth 2015; 15:199.

45. Hodgson J, Spriggs M. A practical account of autonomy: why genetic counseling is especially well suited to the facilitation of informed autonomous decision making. J Genet Couns 2005; 14:8997.

46. Farrell R, Agatisa PK, Mercer B, et al. Balancing risks: The core of women's decisions about noninvasive prenatal testing. AJOB Empirical Bioethics 2015; 6:42-53.

47. Chitty LS, Wright $\mathrm{D}$, Verhoef $\mathrm{TI}$, et al. A prospective cohort study and economic model to evaluate costs and benefits, acceptability and implications at a population level of implementing noninvasive prenatal testing for aneuploidy into routine NHS maternity care. 2015; Manuscript under review.

48. Lau TK, Chan MK, Salome Lo PS, et al. Non-invasive prenatal screening of fetal sex chromosomal abnormalities: perspective of pregnant women. J Matern Fetal Neonatal Med 2012; 25:2616-9.

49. Agatisa PK, Mercer MB, Leek AC, et al. A first look at women's perspectives on noninvasive prenatal testing to detect sex chromosome aneuploidies and microdeletion syndromes. Prenat Diagn $2015 ; 35: 692-8$ 
50. Yotsumoto J, Sekizawa A, Koide K, et al. Attitudes toward non-invasive prenatal diagnosis among pregnant women and health professionals in Japan. Prenat Diagn 2012; 32:674-9.

51. Dondorp W, de Wert G, Bombard Y, et al. Non-invasive prenatal testing for aneuploidy and beyond: challenges of responsible innovation in prenatal screening. Eur J Hum Genet 2015; 23:1592. 52. Royal College of Obsetricians and Gynaecologists. Non-invasive Prenatal Testing for Chromosomal Abnormality using Maternal Plasma DNA (Scientific Impact Paper No. 15). 2014; Available from http://wwwrcogorguk/noninvasive-prenantal-diagnosis-using-cell-free-dna-maternalblood Accessed September 2015.

53. American College of Obstetricians and Gynecologists. Committee Opinion No. 640: Cell-free DNA Screening for Fetal Aneuploidy. Obstet Gynecol 2015; 126:e31-7.

54. Gregg AR, Gross SJ, Best RG, et al. ACMG statement on noninvasive prenatal screening for fetal aneuploidy. Genet Med 2013; 15:395-8.

55. Wilson KL, Czerwinski JL, Hoskovec JM, et al. NSGC practice guideline: prenatal screening and diagnostic testing options for chromosome aneuploidy. J Genet Couns 2013; 22:4-15.

56. Position Statement from the Italian College of Fetal Maternal Medicine: Non-invasive prenatal testing (NIPT) by maternal plasma DNA sequencing. J Prenat Med 2013; 7:19-20.

57. Haymon L, Simi E, Moyer K, et al. Clinical implementation of noninvasive prenatal testing among maternal fetal medicine specialists. Prenat Diagn 2014; 34:416-23.

58. Lewis C, Choudhury M, Chitty LS. 'Hope for safe prenatal gene tests'. A content analysis of how the UK press media are reporting advances in non-invasive prenatal testing. Prenat Diagn 2015; 35:420-7.

59. Truitt AR, Nguyen MHV. Printing Unrealistic Expectations: A Closer Look at Newspaper Representations of Noninvasive Prenatal Testing. AJOB Empirical Bioethics 2015; 6:68-80.

60. Skirton $\mathrm{H}$, Goldsmith L, Jackson L, et al. Non-invasive prenatal testing for aneuploidy: a systematic review of Internet advertising to potential users by commercial companies and private health providers. Prenat Diagn 2015; [Epub ahead of print]. 
61. Kloza EM, Haddow PK, Halliday JV, et al. Evaluation of patient education materials: the example of circulating cell free DNA testing for aneuploidy. J Genet Couns 2015; 24:259-66. 
Table 1: Implications for practice drawn from stakeholder views and published guidance [31,32].

\begin{tabular}{|c|c|c|}
\hline $\begin{array}{l}\text { Pre-test } \\
\text { counselling }\end{array}$ & $\bullet$ & $\begin{array}{l}\text { Provide spoken and written information and emphasise the consent process } \\
\text { Information considered important by parents: test accuracy, sensitivity and } \\
\text { specificity, certainty of the result, risks and alternatives and conditions } \\
\text { included in the test } \\
\text { Use approaches to counselling that alleviate feelings of pressure to test } \\
\text { Promote informed decision making by allowing time for reflection and } \\
\text { through discourse about the impact of results in light of individual values and } \\
\text { beliefs } \\
\text { Provide balanced information on the benefits and limitations of all options } \\
\text { for prenatal testing, including the option of not having a test } \\
\text { NIPT/D should not be presented as a routine test } \\
\text { Safety is a key issue for parents, therefore it is important not to "sell" NIPT/D } \\
\text { because there is no miscarriage risk } \\
\text { Make clear what conditions are included in the test, highlight any differences } \\
\text { in test sensitivity and specificity between test targets and provide neutral and } \\
\text { up-to-date information about the conditions. } \\
\text { For NIPT, explain that this is a screening test, not a diagnostic test and that } \\
\text { invasive testing is recommended to confirm the result } \\
\text { For NIPT, inform women when there is a possibility of incidental findings } \\
\text { about their own health } \\
\text { Check understanding of the information provided in pre-test counselling as } \\
\text { Provide a summary of options for next steps }\end{array}$ \\
\hline $\begin{array}{l}\text { Post-test } \\
\text { counselling }\end{array}$ & & $\begin{array}{l}\text { Provide the opportunity to discuss results and implications face-to-face } \\
\text { Provide support to continue an affected pregnancy if this is what parents } \\
\text { choose } \\
\text { Provide contact details of relevant support groups } \\
\text { Be aware that parents may not have faced the possibility of a positive result } \\
\text { and the implications }\end{array}$ \\
\hline
\end{tabular}


Service

delivery
- Formal regulation of testing and provision of guidance on service delivery from professional bodies is essential

- Ongoing health professional education is important for effective counselling 